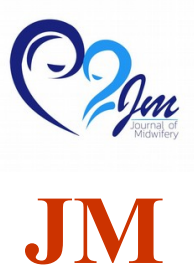

Volume 8 No. 2 (Oktober 2020)

(C) The Author(s) 2020

\title{
PEMBERIAN EDUKASI DAN PENDAMPINGAN KETIDAKNYAMANAN PADA NY.“D” G2P1A0 DI PMB YETTI PURNAMA KOTA BENGKULU
}

\section{PROVIDING ASSISTANCE AND EDUCATION OF DISCOMFORT IN PREGNANCY FOR MRS. "D"G2P1A0 AT THE PMB YETTI PURNAMAIN BENGKULU CITY}

\author{
VRISKY GITA RAMADHAN, KURNIA DEWIANI, DARA HIMALAYA \\ PROGRAM STUDI D3 KEBIDANAN UNIVERSITAS BENGKULU \\ Email: kdewiani@unib.ac.id
}

\begin{abstract}
ABSTRAK
Pendahuluan: Perubahan yang terjadi selama kehamilan membutuhkan suatu proses adaptasi. Proses adaptasi tersebut tidak jarang dapat mengakibatkan ketidaknyamanan.Banyak sekali perubahan yang terjadi selama proses kehamilan, sering kali seorang subjek mengabaikan hal ini sehingga ketika tubuh melakukan perubahanmaka yang terjadi adalah muncul keluhan yang mungkin sebenarnya bisa dicegah jika tubuh seimbang dan mengerti serta siap akan perubahan tersebut. Studi kasus ini bertujuan untuk melakukan asuhan kebidanan komprehensif pada Ny."D" G2P1A0 dengan pemberian edukasi dan pendampingan ketidaknyamanan selama masa kehamilan TM III, persalinan dan nifas di PMB Yetti Purnama Kota Bengkulu. Metode: jenis penelitian ini adalah studi kasus dan menggunakan metode deskriftif dengan tekhnik yang meliputi observasi, anamnessa, pemeriksaan fisik, studi dokumentasi pepustakaan. Pembahasan: Hasil pemberian asuhan kebidanan secara komprehensif pada Ny."D" G2P1A0 dilakukan sesuai rencana kebidanan. Evaluasi akhir berjalan dengan baik tanpa ada hambatan. Proses pengurangan nyeri yang diberikan pada masa kehamilan dengan teknik pijatan endorphin dan senam hamil. Persalinan dilakukan pendampingan untuk mengurangi nyeri persalinan, audio murottal, relaksasi pernafasan dan massase effleurage. Saat masa nifas dilakukan kompres dingin untuk mengurangi nyeri perenium. Berdasarkan asuhan yang diberikan semua berjalan baik dan normal hingga 2 minggu masa nifas berjalan lancar. Klien mendapatkan penyuluhan tentang persiapan penggunaan alat kontrasepsi dan klien akan memilih KB dengan Suntik setelah masa nifas berakhir. Kesimpulan: Asuhan kebidanan komprehensif yang diberikan pada Ny D telah diberikan sesuai dengan kebutuhan klien yang didukung teori evidence based dalam kebidanan dan asuhan selama 12 minggu berjalan lancar subjek dan bayi sehat.
\end{abstract}

Kata kunci: asuhan kebidanan, ketidaknyamanan 


\begin{abstract}
Introduction: The transformation during pregnancy requires a process of adaptation. The progress often causes discomfort and there are so many changes during the pregnancy process, generally, the mother neglects it when the body makes changes. The complaints might be prevented by the body balances and understand to prepare for these changes. . The aims of this study is to provide comprehensive midwifery care for Mrs. "D" G2P1A0 by providing education and assistance for discomfort during TM III pregnancy, childbirth, and postpartum at PMB Yetti Purnama Bengkulu City. Methods: The research type was a study case and used a descriptive method with the observation, anamnesis, physical examination, the study of library documentation techniques. Results and Discussions: The results of providing comprehensive midwifery care to Mrs. "D" G2P1A0 were carried out according to the midwifery plan. The final evaluation has been done without any difficulty. The processes of reducing pain during pregnancy were implemented by using endorphin massage techniques and pregnancy exercises. Assisted childbirth was provided to reduce labor pain such as murottal audio, respiratory relaxation, and massage effleurage. During the puerperium, cold compresses were used to reduce perenium pain. Based on the care given, the processes have been done successfully and normally during 2 weeks of the postpartum period. The clients received counseling on preparation for contraceptive use and clients chose injection contraception after the postpartum period ends. Conclusions: The comprehensive midwifery care to Mrs. D has been accustomed according to client needs supported by evidence-based theory in midwifery and the processes have been compassed during 12 weeks with the results were a healthy mothers and babies.
\end{abstract}

\title{
Keywords: midwifery care, discomfort
}

\section{PENDAHULUAN}

Kehamilan didefenisikan sebagai fertilisasi atau penyatuan spermatzoadan ovum dilanjutkan dengan nidasi atau implantasi. Kehamilan normaldihitung dari saat fertilisasi hingga lahirnya bayi, akan berlangsung dalam waktu 280 hari(40 minggu atau 9 bulan 7 hari ). Kehamilan terbagi dalam tiga trimester dimana trimester pertama berlangsung dalam 12 minggu, trimester kedua berlangsung selama 15 minggu (minggu ke-13 hingga-27), dan trimester ketiga 13 minggu (minggu ke-28 hingga ke40) (Farid, 2015). Perkembangan hasil pembuahan berlanjut dari hari ke hari dan diikuti oleh semakin berkembangnya janin didalam rahim subjek, sejalan dengan perkembangan janin dalam rahim maka terjadi perubahan fisik dan psiklogis subjek. Perubahan yang terjadi ini akan menimbulkan berbagai keluhan ketidaknyamanan pada subjek. Banyak sekali perubahan yang terjadi selama proses kehamilan, seringkali seorang subjek mengabaikan hal ini sehingga ketika tubuh melakukan perubahan maka yang terjadi adalah muncul keluhankeluhan yang mungkin sebenarnya bisa dicegah jika tubuh seimbang dan mengerti serta siap akan perubahan tersebut.

Perubahan yang terjadi selama kehamilan membutuhkan suatu proses adaptasi. Proses adaptasi tersebut dapat mengakibatkan ketidaknyamanan (Deswani, 2018). Subjek hamil selama masa kehamilannya sangat membutuhkan tubuh yang segar dan bugar agar dapat menjalankan aktivitas, senam hamil merupakan terapi latihan gerak untuk menjaga stamina subjek selama kehamilan dan mempersiapkan subjek secara fisik maupun mental untuk menghadap persalinan (Farid,2015). Senam hamil dapat menurunkan ketidaknyamanan selama kehamilan dan mempersiapkan fisik dan psikologis subjek untuk melahirkan (Hidayati, 2019). Hasil penelitian Hartati (2019) menunjukkan bahwa ada perbedaan skor nyeri punggung sebelum dan sesudah pijat 2 
endorphin pada lkelompok eksperimen, pijat endorfin efektif mengurangi nyeri punggung pada wanita hamil. Ketidaknyaman sering buang kecil juga sering dialami wanita hamil, karena tertekannya kandung kemih oleh uterus yang semakin membesar dan menyebabkan kapasitas kandung kemih berkurang serta fekuensi berkemih meningkat. Penatalaksanaan keluhan ini dengan cara, bidan dapat mejelaskan pada subjek bahwa perubahan fisiologis kehamilan TM III salah satunya sering berkemih merupakan hal normal akibat dari perubahan yang terjadi selama kehamilan, serta memberitahu subjek untuk mengatur pola hidrasi yaitu perbanyak minum disiang hari dan menganjurkan subjek mengurangi asupan cairan dimalam hari (Farid, 2015). Ketidaknyamanan pada kehamilan antara lain, sering BAK $40 \%$, konstipasi $40 \%$, nyeri perut bawah 10-30\%,nyeri punggung 20-25\%, varises $40 \%$, kram kaki 50\%, gangguan tidur 79\% (Farid,2015).

Ketidaknyaman juga dapat terjadi di proses persalinan. Setiap wanita menginginkan persalinan yang aman dan nyaman, adanya ketakukan dan suasana yang tidak bersahabat akan mengakibatkan ketegangang otot dan rasa nyeri. Nyeri dalam persalinan dan kelahiran adalah bagian dari respon fisiologis yang normal terhadap beberapa faktor. Nyeri yang terjadi pada kala I terutama disebabkan oleh dilatasi serviks dan distensi segmen uterus bawah (Kurniarum, 2016).Upayamengurangi nyeri pada saat proses persalinanmenurut penelitian Susilawati (2017) dilakukan pengamatan tentang gejala intensitas nyeri kala I fase aktif yang diberikan metode relaksasi pernapasan lebih rendah dibandingkan pada subjek yang tidak diberikan metode relaksasi pernapasan.Penelitian Yana (2015) menunjukkan bahwa terapi murottal Al-quran efektif dalam menurunkan intensitas nyeri persalinan. Penelitian lainmenunjukkan bukti ada pengaruh terapi musik klasik terhadap instensitas nyeri pada persalinan (Sunarsih, 2017). Purnama(2019) meneliti posisi juga dapat membantu mengurangi rasa nyeri pada persalinan, dengan hasil terdapat perbedaan pengaruh posisi tegak dan posisi litotomi terhadap penurunan nyeri persalinan.

Penelitian lain menunjukkan bukti bahwa kehadiran seseorang pendamping pada saat persalinan dapat menimbulkan efek positif, yaitu adanya pendampingan persalinan terdapat hubungan yang bermakna antara pendampingan suami dengan intensitas nyeri persalinan kala I fase aktif (Adam, 2015). Penelitian (Wulandari, 2015) setelah diberikan massasse effleurage terdapat penuruan skala nyeri sedang, ini menunjukkan bahwa massase effleurage dapat dilakukan untuk meredakan nyeri persalinan kala 1 fase aktif. Proses kelahiran bayi sudah berakhir,makasubjek akan memasuki periode nifas.Ketidaknyamanan nyeri perenium saat masa nifas ialah nyeri akibat luka atau jahitan perenium.Upaya yang dilakukan untuk mengatasi yaitu, dengan cara kompres dingin. Terapi kompres dingin lebih efektif dalam mengatasi nyeri luka perenium pada subjek post partum (Susilawati, 2019).

Bidan memiliki peran penting dalam mengatasi keluhan ketidaknyaman pada subjek hamil hingga nifas.Melalui asuhan yang berkelanjutan atau Continuty of care (CoC) diharapkan dapat membantu subjek melewati kehamilan hingga nifas dengan aman dan nyaman. Praktik Mandiri Bidan (PMB) Yetti Purnama salah satu lahan praktik bidan yang berada di wilayah kota Bengkulu yang dapat memberikan asuhan kebidanan. Jumlah pasien hamil pada bulan januari sampai bulan februari tahun 2020 ada sebanyak 25 subjek hamil, calon persalinan sebanyak 5 orang, dan 1 orang yang memiliki keluhan ketidaknyamanan. Survey awalpada Ny."D"G2P1A0 yang memiliki keluhan ketidaknyaman pada kehamilan TM III, Ny.'D"mengeluhkan saat ini merasakan nyeri pinggang dan mudah lelah saat beraktivitas serta subjek mengeluh gangguan tidur pada malam hari karena sering ke kamar mandi untuk buang air kecil, karena adanya keluhan tersebut subjek merasa tidak nyaman serta gelisah, dengan keluhan demikian Ny."D" membutuhkan pendampingan dan edukasi 
tentang ketidaknyaman dan cara mengurangi atau mengatasi keluhan tersebut. Berdasarkan dari data latar belakang di atas adanya kasus ketidaknyamanan pada kehamilandi PMB Yetti Purnama maka penulis tertarik mengangkat studi kasus dengan judul "Pemberian Edukasi dan Pendampingan Ketidaknyaman pada Ny."D"G2P1A0di PMB Yetti Purnama tahun 2020"

\section{METODE PENELITIAN}

Metode penelitian yang digunakan pada penelitian adalah deskriftif. Pendekatan yang digunakan pada penulisan karya ilmiah adalah studi kasus. Studi kasus merupakan jenis pendekatan yang digunakan untuk menyelidiki dan memahami informasi yang kemudian diolah untuk mendapatkan sebuah solusi agar masalah yang dihadapi terselesaikan. (Sugiyono, 2014). Tehnik pengumpulan data meliputi observasi, anamnessa, pemeriksaan fisik, studi dokumentasi kepustakaan. Lokasi penelitian ini dilakukan di Praktik Mandiri Bidan (PMB)Yetti Purnama Kota Bengkulu. Waktu pelaksanaan dilakukan pada bulan Maret sampai bulan Mei 2020. Subjek studi kasus adalah subjek hamil Trismester III yakni Ny."D" G2P1Ao yang pada saat hamil mengeluh nyeri bagian pinggang dan mudah lelah saat beraktivitas serta subjek mengeluh gangguan tidur pada malam hari dan sering ke kamar mandi ingin BAK, dan pada saat persalinan subjek mengeluhkan ketidaknyamanan berupa nyeri persalinan, serta pada masa nifas subjek memiliki keluhan nyeri pada area perinium. Adanya beberapa keluhan tersebut subjek merasa tidak nyaman serta gelisah, dengan demikian memerlukan pemberian edukasi dan pendampingan ketidaknyamanan selama masa kehamilan, persalinan hingga 2 minggu masa nifas di PMB Yetti Purnama kota Bengkulu. Alat dan bahan yang digunakan yaitu terdiri dari : Alat yang digunakan untuk melakukan wawancara adalah format asuhan kebidanan pada subjek hamil, bersalin dan nifas serta bayi baru lahir. Untuk pemeriksaan dan penatalaksanaan meliputi : tensimeter, steteskop,dopler, timbangan berat badan, medline, therometer, jam, partus set, heacting set, pemutar audio, massage set. Untuk melakukan dokumentasi: catatan medik atau status pasien, buku KIA, patograf. proses penelitian ini, telah memerhatikan etika dalam penelitian yaiutu Respect for persons, Beneficence dan Non malefiecence, Justice

\section{HASIL PENELITIAN}

Keluhan ketidaknyamanan yang subjek rasakan saat kehamilan TM III adalah nyeri punggung bagian bawah sejak uk 35 minggu dan sering kencing sejak uk 33 minggu. Hasil pemeriksaan data objektif didapat hasil $\mathrm{K} / \mathrm{U}$ : Baik Kesadaran: CM TD: 110/80 mmhg N: $83 \mathrm{x} / \mathrm{m} \mathrm{S}: 36,5^{\circ} \mathrm{C} \mathrm{R}: 23 \mathrm{x} / \mathrm{m}$ TB: $160 \mathrm{x} / \mathrm{m} \mathrm{BB}$ sebelum: $59 \mathrm{~kg}$ BB sekarang : $69 \mathrm{~kg}$ LILA : 29 cm IMT: 28,39 Leopold I: TFU Pertengahan px pusat $(31) \mathrm{cm}$ pada bagian atas perut subjek teraba bulat, lembut, tidak melenting (bokong), Leopold II: pada bagian kanan perut subjek teraba bagian memanjang keras (punggug) dan pada bagian perut kiri subjek teraba bagian-bagian kecil janin, Leopold III: Pada bagian bawah perut subjek teraba bulat, keras, masih bisa digoyangkan (kepala), Leopold IV: Kepala belum masuk PAP (konvergen) DJJ: 140x/menit. Analisa/kesimpulan kondisi terkait ketidaknyamanan yaitu G2P0A0 hamil 39 minggu, janin tunggal hidup, presentasi kepala, keadaan umum subjek dan janin baik.

Penatalsanaaan yang diberikan pada subjek terkait ketidaknyamanan yang dirasakan yaitu Mendiskusikan faktor penyebab nyeri puggung dan sering BAK yang dirasakan subjek karena rahim yang semakin membesar, sehingga beban ke depan semakin bertambah dan membuat tulang punggung teregangkan, sedangkan sering kencing yang dirasakan disebabkan oleh kepala janin sudah turun ke pintu atas panggul dan terjadi penekanan pada kantung kemih sehingga membuat subjek sering ingin BAK, b) menilai tingkat nyeri punggung dengan menggunakan skala VAS yang berada 
diskala 7, c) Mendiskusikan tetang cara mengurangi ketidaknyamanan yang subjek rasakan seperti senam hamil, pijat endorphin, mengatur pola hidrasi di malam hari, d) Mendemonstrasikan senam hamil dan pijat endorphin bersama subjek dan suami, e) Mendiskusikan personal hygiene khususnya pada bagian genitalia, menganjurkan subjek untuk rutin mengganti celana dalam atau jika terasa lembab, hal ini agar kebersihan personal hygiene subjek terjaga dan tidak terjadi infeksi. Evaluasi asuhan yang diberikan yaitu subjek mengalami penurunan skala nyeri sejak hari ke 3 yang dinilai melalui skala VAS turun ke skala 3 post pemberian berupa senam hamil dan pijatan endhorpin dan semakin lebih rileks dan nyaman hingga akhir kehamilan skala VAS menunjukan skala 3. Keluhan subjek berupa sering BAK dimalam hari dan susah tidurpun jauh lebih berkurang.

Setelah melewati proses kehamilan secara mature maka subjek memasuki periode persalinan. Keluhan ketidaknyaman yang dirasakan subjek adalah nyeri akibat kontraksi persalinan. Subjek mengatakan merasakan mules-mules sejak pukul 16.30 dan nyeri punggung menjalar ke perut bagian bawah disertai keluar lendir bercampur darah. Hasil pemeriksaan Keadaan umum dan TTV dalam batas normal. Leopold I: TFU pertengahan px pusat $(30) \mathrm{cm}$ pada bagian atas perut subjek teraba bundar, lembut, tidak melenting (bokong) Leopold II: Pada bagian kanan perut subjek teraba bagian memanjang (punggung) dan pada bagian perut kiri subjek teraba bagian-bagian kecil janin, Leopold III: Pada bagian bawah perut subjek teraba bulat, keras, tidak bisa digoyangkan (kepala), Leopold IV: (divergen) $3 / 5$ bagian DJJ: $145 \mathrm{x} /$ menit Kontraksi: 3x/10'/30" DJJ: 149 x/m, 2) Pemeriksaan dalam a) Vulva/vagina: tidak ada pembesaran kelenjar bartolini, b) Portio: Tipis, c) Pembukaan: $5 \mathrm{~cm}$, c) Presentasi: Kepala d) Ketuban: (+) e) Penurunan: Hodge II. Analisis yang ditegakkan yaitu G2P1A0 hamil 40 minggu 3 hari, intra uteri, janin tunggal hidup, presentasi kepala, keadaan umum subjek dan janin baik, inpartu kala I fase aktif.

Penatalaksanaan yang diberikan pada untuk mengatasi keluhan ketidaknyaman berupa nyeri perslinan yaitu, mulai dari mengukur skala nyeri menggunkan skala VAS, skala nyeri berada di skala 7 . Menghadirkan pendamping persalinan dan menginformasikan tugas pendamping persalinan dengan melakukan massase effleurage Ketika subjek mengalami nyeri. Memutar audio murottal selama 15 menit dengan ayat al-fatihah, arrahman, al-ikhlas, al-falaq, an-nas. Mengajarkan subjek melakukan relaksasi pernafasan, Mendiskusikan mobilisasi dan posisi yang nyaman dan menganjurkan pendampingan persalinan untuk memberikan makan atau minum disela kontraksi. Evaluasi dilakukan Kembali setelah 2 jam setelah diberikan tehnik pengurangan nyeri, dan skala VAS menunjukkan penurunan menjadi 5 , subjek merasa lebih tenang dan siap menghadapi persalinan. Proses kala II, Kala II, III, dan IV dapat dilewati secara lancar tetapi terdapat luka perinium derajat 2 dan telah dijahit. Bayi lahir menangis kuat, bergerak aktif dan sehat.

Memasuki masa postpartum hari pertama subjek memiliki keluhan ketidaknyaman berupa nyeri pada daerah perinium akibat adanya jahitan luka. Subjek mengatakan tidak ada masalah pada pemberian ASI. Hasil pemeriksaan didapatkan hasil KU Baik, TD 110/80 mmhg, N 85 x/menit, R 20 x/menit, S $36,5^{\circ} \mathrm{C}$, ASI (+). Kontraksi Baik TFU 2 jari dibawah pusat Lochea rubra $(30 \mathrm{cc})$. BAB/BAK +/+, Luka jahitan basah. Data analisa pada saat nifas P2A0 post partum 1 hari. Penatalaksanaan awal adalah dengan mengukur skala nyeri dengan VAS, diperoleh hasil skala 4. Memberikan penjelasan pada subjek tentang perawatan luka perineum dengan menjaga personal hygiene dan pemberian kompres air dingin sebanyak 2 kali, pagi dan sore selama 5 menit. Mendiskusikan tentang kebutuhan nutrisi untuk pemulihan tubuh dan percepatan penyembuhan luka. Evaluasi dilakukan pada hari ke 4 menggunakan skala VAS hasil menunjukkan skala nyeri adalah 0 . Hal ini 
menunjukkan bahwa ketidaknyaman subjek terhadap nyeri perinium akibat jahitan luka pada hari 4 sudah tidak dirasakan, dan subjek dapat melewati masa postpartum dengan normal dan bahagia.

\section{PEMBAHASAN}

Pendampingan dan pemberian edukasi ketidaknyamanan selama masa kehamilan, persalinan dan nifas pada Ny."D" umur 30 tahun G2P1A0 dimulai sejak 26 maret 2020 dengan metode SOAP, (subjektif, objektif, Analisa dan penatalaksanaan) telah dilaksanakan dengan komprehensif. Asuhan diberikan sejak dikehamilan yaitu Ny " $D$ " mengeluh adanya ketidaknyamanan nyeri punggung dan sering buang air kecil. Penatalaksanaan diberikan berupa penjelasan pada subjek bahwa nyeri punggung yang subjek rasakan adalah normal, kerena kepala bayi turun ke pintu atas panggul. Selama kehamilan, berat badan akan bertumpu kedepan, sehingga menggeser pusat dari gravitasi dan pusat stress. Kedudukan dari sendi dan otot terutama pada panggul dan punggung bagian bawah, sehingga dapat membuat subjek hamil menjadi kurang stabil dan kehilangan keseimbangannya terutama pada kehamilan lanjut, hal ini dapat mengakibatkan sakit pada punggung (Farid, 2015). Melakukan tekhnik pengurangan nyeri dilakukan senam hamil dan pijat endorphin.

Sesuai dengan hasil penelitian (Handayani, 2018) bahwa senam hamil yang dilakukan dapat mengurangi ketidaknyamanan pada keluhan seperti nyeri punggung, hasil yang didapat sebelum dilakukan senam hamil pada subjek rata-rata nyeri 83,3 dan setelah dilakukan senam hamil didapatkan menurun ke 16,7. Subjek dilakukan skala pengurangan nyeri menggunakan VAS, sebelum dilakukan senam hamil ada diskala 7 dan setelah dilakukan senam hamil skala nyeri berada di skala 3 . Sebelum penatalaksanaan dilakukan pengukuran skala VAS untuk mengukur tingkat nyeri. Tingkat nyeri berada diskala 7 dan setelah dilakukan pijatan endorphin dan senam hamil skala VAS menurun menjadi skala 3. Sesuai dengan hasil penelitian yang menunjukkan bahwa ada perbedaan skor nyeri punggung sebelumnya 3,52 dan sesudah pijat endorphin pada kelompok eksperimen mengalami penurunan 1,84 , pijat endorfin efektif mengurangi nyeri punggung pada wanita hamil (Hartati, 2019). Menjelaskan pada subjek bahwa sering buang air kecil BAK yang dialami adalah normal karena kepala janin turun ke panggul sehingga menekan kandung kemih sehingga membuat subjek ingin buang air kecil. Teori yang dikemukakan (Deswani, 2018) bahwa Penekanan pada kantung kencing oleh kepala bayi menimbulkan keluhan sering buang air kecil. Hal ini adalah normal dan biasa dirasakan pada kehamilan kurang dari 16 minggu dan pada kehamilan diatas 32 minggu. Melewati proses kehamilan, Ny."D" memasuki proses persalinan. Proses kala I Ny."D" ingin didampingi suami karena subjek merasa nyaman dan semangat dengan kehadiran suami dalam menghadapi proses persalinan. Hasil penelitian yang didapatkan Subjek yang sedang dalam proses persalinan didampingi suami akan merasa lebih semangat dan terdapat hubungan yang bermakna antara pendampingan suami dengan instensitas nyeri persalinan Kala I (Adam, 2015). Selain pendamping persalinan, pada kala I Ny."D" juga diberikan audio untuk mendengarkan music murottal selama 15 menit, Ny.'D” merasa tenang mendengar audio murottal. Hal ini dikemukakan oleh hasil penelitiaan (Yana, 2015) terapi murottal Al-quran terhadap penurunan nyeri persalinan kala I fase aktif. mendengarkan murotal Alquran selama 15 menit yang terdiri dari bacaan surat Al-fatihah selama 1 menit, surat Ar-rahman selama 12 menit, surat al-ikhlas, al-falaq, dan surat an-nas 2 menit.

Ny."D" juga diberikan pengurangan nyeri kala I pembukaan $5 \mathrm{~cm}$ dengan massase effleurage yang dilakukan suami dengan pengukuran skala nyeri menggunakan VAS, sebelum dilakukan massase effleurage berada diskala 8 dan setelah diberikan pengurangan nyeri skala nyeri menurun diskala 4 . Hal ini 
sejalan dengan hasil penelitian (Wulandari, 2015) subjek yang tidak diberikan massase effleurage dengan skala nyeri berat $78,3 \%$, setelah diberikan 87 massasse effleurage terdapat penuruan skala nyeri sedang $69,6 \%$, ini menunjukkan bahwa massase effleurage dapat dilakukan untuk meredakan nyeri persalinan kala 1 fase aktif. Ny."D" dibimbing untuk melakukan relaksasi pernafasan ketika ada kontraksi yang bisa menurunkan nyeri persalinan pada subjek. Hasil penelitian (Herawati, 2016) nyeri persalinan dapat dikurangi dengan tekhnik relaksasi. Tekhnik relakasasi yang paling efektif dalam pengurangan nyeri pada persalinan kala 1 yaitu relaksasi pernapasan dengan cara subjek melakukan tarikan nafas dari mulat saat adanya his dan hembuskan melalui mulut. Ny."D" diminta untuk menunjukkan skala nyeri persalinan pada VAS berada diskala 7, setelah diberikan tehnik pengurangan nyeri dengan tehnik massase effleurage, audio murottal, relaksasi pernafasan, dan pendampingan suami skala VAS menurun menjadi skala 6.

Memasuki kala II membimbing subjek meneran ketika ada mules dan tetap menganjurkan subjek melakukan relaksasi pernafasan. Ny."D" dilakukan pertolongan secara APN. Teori menunjukkan kala II disebut kala pengeluaran. Kala ini dimulai dari pembukaan lengkap $10 \mathrm{~cm}$ sampai bayi lahir (Rosyati,2017). Proses kala III dilakukan sesuai manajemen aktif kala III, serta penjahitan luka perenium. Teori yang dikemukakan (Rosyati,2017) proses pengeluaran plasenta adanya tanda-tanda lepasnya plasenta yaitu terjadi perubahan bentuk uterus tinggi fundus uteri, tali pusat memanjang keluar melalui vagina adanya semburan darah secara tiba-tiba. Memasuki kala IV mengobservasi Ny."D" selama 2 jam pertama setiap 15 menit, dan 2 jam kedua setiap 30 menit. Teori yang dikemukakan (Rosyati, 2017). Observasi yang dilakukan pada kala IV adalah, tingkat kesadaran, pemeriksaan tanda-tanda vital, tekanan darah, nadi dan pernapasan. Mengecek kontraksi uterus dan mengkaji pendarahan, dikatakan normal jika tidak lebih melebihi 500 cc. Penatalaksanaan nifas pada Ny."D" diberikan kompres dingin pada luka jahitan daerah perinium yang dapat mengurangi nyeri perenium, selin itu diberikan juga cara perawatan luka agar cepat kering. Sebelum dilakukan tekhnik pengurangan nyeri skala VAS berada diskala 4 dan setelah diberikan asuhan selama 3 hari subjek mengalami pengurangan nyeri menurun di skala 0 . Subjek tetap dberikan pendampingan untuk tetap memberikan ASI Eksklusif. Mengingatkan subjek untuk mengonsumsi makanan yang bergizi dan seimbang untuk ibu menysusui, peraatan bayi sehari-hari, dan menganjurkan subjek untuk istirahat yang cukup. Pemantauan dilakukan sampai dengan 2 minggu masa nifas, setelah melewati 2 minggu, subjek mulai edukasi mengenai alat kontrasepsi yang akan digunakan setelah masa nifas. Subjek megatakan akan memilih kontrasepsi KB suntik 3 bulan yang tidak akan memengaruhi produksi ASI. Evaluasi berdasarkan asuhan atau penatalaksanaan yang diberikan pada Ny."D" berjalan lancar sehingga subjek dan bayi sehat.

\section{KESIMPULAN}

Penatalaksanaan asuhan yang diberikan pada subjek sesuai dengan rencana yang telah disusun antara lain : Pada masa kehamilan subjek diberikan pendampingan dan edukasi dalam melakukan gerakan senam hamil dan pijat endorphin untuk mengurangi keluhan nyeri punggung dan sering BAK yang subjek rasakan selama kehamilan TM III. Asuhan telah dilakukan dan berjalan dengan baik, subjek merasa nyaman dan rileks setelah diberikan tekhnik pengurangan nyeri. Selain melakukan senam hamil dan pijatan endorphin, subjek dianjurkan untuk mengatur pola hidrasi yang bertujuan untuk mengurangi rasa ingin BAK saat malam hari, dan juga makan-makanan yang bergizi. Proses persalinan yang didampingi suami membuat subjek lebih tenang dan semangat menjalani persalinan, subjek juga di berikan audio untuk mendengarkan music murotal yang membuat 
subjek rileks. Selain itu subjek juga dilakukan massase effleurage yang membuat nyeri punggung subjek berkurang saat persalinan. Ny."D" dilakukan heacting perenium, maka dari itu subjek dilakukan tekhnik pengurangan nyeri menggunakan kompres dingin, selama diberikan subjek merasa terlihat tenang dan subjek mengatakan nyeri jahitan perenium berkurang sehingga sudah dapat beraktifitas ringan seperti mengurus anaknya mengganti popok dan pakaian bayi. Kunjungan nifas 2 minggu subjek diberikan edukasi alat kontrasepsi yang dapat digunakan selama menyusui. subjek. Subjek akan memilih KB suntik 3 bulan yang setelah masa nifas. Dapat disimpulkan bahwa evaluasi asuhan tentang pendampingan dan edukasi ketidaknyamanan selama kehamilan TM III, persalinan dan 2 minggu nifas pertama pada Ny."D" berhasil dilakukan tanpa adanya hambatan.

\section{SARAN}

Asuhan kebidanan komprehensif ini dapat dijadikan masukan untuk meningkatkan pelayanan berbasis asuhan sayang ibu pada sejak masa hamil, bersalinan dan nifas dengan ketidaknyamanan di PMB Yetti Purnama Kota Bengkulu, serta tetap mempertahankan sarana kelengkapan ruang bersalin dan alat penunjang lainnya, mengikuti pelatihan-pelatihan terupdate guna menunjang asuhan sayang ibu berbasis evidence based.

\section{DAFTAR PUSTAKA}

Adam J. Umboh JM. Hubungan antara umur, parietas dan pendampingan suami dengan intensitas nyeri persalinan kala I Fase aktif deselelerasi. JIKMU. 2015;2(5): 404-413 [diunduh pada tanggal 29 februari 2020]

Anwar M, Ali BR. Prajitno P. Ilmu Kandungan. Edisi ke 3. Jakarta:PT Bina Pustakan Sarwono Prawiroharjo. 2018

Cunningham FG, Gant, NF, Leveno KJ, Gilstrap LC, Hauth JC, Wenstrom,
KD. Obstetri Williams. Edisi 21.2006

Damayanti IK, Maita L, Triana A, AfniR .Asuhan kebidanan komprehensif pada subjek bersalin dan bayi baru lahir. Deepublish, Yogyakarta; 2014

Deswani, Desmamita U, Mulyanti Y. Buku ajar asuhan keperawatan prenatal dengan pendekatan neurosains. Wineka Media. Malang; 2018

Dewiani K, Purnama Y. Pengaruh kompres daun kubis dingin terhadap penurunan intensitas nyeri dan pembengkakan payudara pada subjek post partum. Jurnal keperawatan muhammadiyah Bengkulu. 2018;2(6): 488-492 [diunduh pada tanggal 20 februari 2020]

Farid H. Buku ajar asuhan kebidanan berbasis bukti. Jakarta: Sagung Seto; 2015

Hariyanti BT, Kristina SA. Perbedaan produksi ASI pada akseptor KB suntik kombinasi dan Progestin. Journal Of Nursing Care. 2017;1(2): 36-41 [diunduh pada tanggal 11 maret 2020]

Hartati R, Rahayu AOS, Sari FT, Islami AP. Increasing the comfortable feel for pregnant womenthrough the endorphin massage. Conference Series. 2019;1(10):1-6 [diunduhpadatanggal 17 februari 2020]

Herawati R. Evaluasi tekhni krelaksasi yang paling efektif dalam penatalaksanaan nyeri persalinan kala 1 terhadap keberhasilan persalinan normal.Jurnal Maternity and Neonatal. 2016;2(2): 102-113 [diunduh pada tanggal 9 februari 2020]

Hidayati U. Senam hamil untuk masa kehamilan dan persiapan persalinan. Jurnal Ilmiah Kesehatan dan Aplikasinya. 2019;2(7): 8-15 [diunduh pada tanggal 12 februari 2020]

Indrayani $\mathrm{T}$, Arselina N. pengaruh terapi musik terhadap intensitas nyeri persalinan kala I fase aktif. Jurnal ilmu dan budaya. 2018;58(41): 6788-6743 [diunduh pada tanggal 12 maret 2020]

Jamil S N, Sukma F, Hamidah. Buku ajar 
asuhan kebidanan pada neonatus, bayi, balita, dan anak prasekolah. Jakarta; Fakultas Kedokteran dan Kesehatan Universitas Muhammadiyah; 2017

Kemenkes RI. Pedoman pelayanan keluarga berencana pasca persalinan di fasilitas kesehatan. Jakarta; 2014

Kurniarum A. Modulbahan ajar asuhan kebidanan persalinan dan bayi baru lahir. Jakarta: Pusdik SDM Kesehatan Kementerian Kesehatan RI; 2016 Lowdermilk PC. Buku ajar keperawatan maternitas. Edisi ke 8. Singapore: PT Salemba Medika;2013

Oktarina O. Buku ajar asuhan kebidanan persalinan dan bayi baru lahir. Yogyakarta: Deepublish; 2016

Palifiana DA, Wulandari S. Hubungan ketidaknyamanan dalam kehamilan dengan kualitastidur subjek hamil trimester III. 2018;5(8): 31-40 [diunduh pada tanggal 5 februari 2020]

Purnama Y, Johanes Cornelius Mose, Herman H. The effect of the BC-MK15 Birth chair on the labor Pain Intensity in Multipara.Global Medical and Health Communication. 2018;3(6): 155-161 [diunduh pada tanggal 18 februari 2020]

Purnama Y, Kurnia D. Pengaruh posisi tegak terhadap intensitas nyeri persalinan pada primipara di bidan praktik mandiri (BPM) kota Bengkulu.Journal Of Midwifery. 2019;1(7): 52-59 [diunduh pada tanggal 12 februari 2020]

Rahayu S, Prijatni I. Modul bahan ajar cetak kebidanan pratikum kesehatan reproduksi dan keluarga Berencana. Jakarta: Pusdik SDM Kesehatan Kementerian Kesehatan RI; 2016

Rahmawati N, Rosyidah T, Maharani A. Hubungan pelaksanaan senam hamil dengan ketidaknyamanan subjek hamil trimester III. Journal involusi Kebidanan. 2016;12(7): 41-50 [diunduh tanggal 2 maret 2020]

Rahmaniar A, Halik AA, Purnamasari N. Pengaruh senam nifas terhadap intensitas nyeri perenium dan kecemasan subjek postpartum di RSIA pertiwi makassar. Jurnal kedokteran. 2019;2(4): 11-19 [diunduh pada tanggal 2 maret 2020]

Robin B. Thomas. A Pilot Study of Partner chair massage effects on perinatal mood, anxiety, and pain.Human Services and Health Promotion Sciences. 2019;2(12): 3-11 [diunduh pada tanggal 17 februari 2020]

Sunarsih, Maternyti D, Astusi NPR. Terapi musik klasik mengurangi nyeri pada kala I persalinan. Jurnal Dunia Kesmas. 2017;6(1): 49-54 [diunduh pada tanggal 12 maret 2020]

Suryani P, Handayani I. Senam hamil dan ketidaknyamanan subjek hamil trimester ketiga. Midwife Journal. 2018;1(5): 33-39 [diunduh pada tanggal 10

februari 2020] Susilawati E, Ilda W. Efektifitas kompres hangat dan kompres dingin terhadap intensitas nyeri luka perenium pada subjek post partum. Journal Of Midwifery Science. 2019;1(3):7-14 [diunduh pada tanggal 13 februari 2020]

Susilawati E. Pengaruh metode relaksasi pernapasan terhadap intensitas nyeri pada persalinan kala I faseaktif.Journal of Midwifery Science. 2017;2(1): 7479 [diunduh pada tanggal 20 februari 2020]

Susilo R, Feti K. Buku ajar panduan asuhan nifas dan evidence based practice. Yogykarta: Deepublish; 2017

Wahyuningsih S. Buku ajar asuhan keperawatan post partum. Deepublish Publischer: Yogyakarta; 2019

Wulandari P, Hiba NDP. Pengaruh massase effleurage terhadap pengurangan nyeri persalian kala 1 fase aktif. Jurnal Keperawatan Maternitas. 2015;1(3): 5967 [diunduh pada tanggal 11 maret 2020]

Yana R. Utami S, Safri.Efektifitas terapi murottal al- quran terhadap itensitas nyeri persalinan kala I fase aktif. JOM. 2015;2(2): 1372-1380 [diunduh pada tanggal 12 maret 2020]

Yanti D. Buku ajar konsep dasar kehamilan. Bandung: Cv. PT Refika Aditama; 2017. 